the College basely panders. We agree with "Junius" that the law is unnecessarythat it is unjust and derogatory to the true dignity of the College.-Another Correspondent observes, that the practice of lecturing on midwifery, to a mixed cless of males and females, is attended with much inconvenience. We should think so.

A Student of Edinburgh, who complains of the irony and the remarks of Scotus, should recollect, that he being in London and the latter at Edinburgh, may account for the descrepancy of opinion which seems to exist between them, as to the scarcity or not of subjects at the northern school. With regard to his observations on the fra.. ternity of Surgeon's-square, we can only say, that we have a great respect for some of the parties, and that we do not think the remarks of Scotus quite so sweeping as he. All general statements must be taken cum grano salis, in the scale of comparison.

Mr. Stafford Smith, of Cambridge, communicates a most severe and obstinate case of constipation, the substance of which is as follows :-

A child, nine years of age, was brought to him by the mother, who said, that of late the child's bowels had become very costive, and requested some aperient medicine. Fifteen grains of jalap were administered without effect, and on the following day a similar quantity. V arious other purgatives were had recourse to, with no very satisfactory result for about a fortnight, when the bowels were brought again to a regular mode of action, and the child did well. Mr. Smith says, "If I mistake not, the quantity of calomel exhibited in this time, was $279 \frac{1}{2}$ grains, which, so far from exciting ptyalism, did not perceptibly affect the gums of the child. In addition to this active remedy, 98 grains of scammony, 9 grains of jalap,

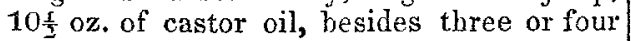
ounces of tincture of senna were taken, before the constipation and pain could be effectually relieved, and the bowels restored to their usual regularity. It would appear also, that $70 \frac{1}{2}$ grains of antimonial powder, and $7_{\frac{1}{2}}$ grains of opium, were administered during the period above mentioned."

Mr. Smith asks why the evacuations presented so perfectly a green colour? In reply to which, we are not aware that any satisfactory answer can be given in the present state of our information. It might not be amiss to state here, that in some cases which we have recently seen, we have found friction on the abdomen a most effectual source of relief; and in very obstinate cases, in which the contents of the rectum were almost of the colour and consistence of lalf baked clay, the abdomen greatly distended, and the clild in much pain, we have succeeded in removing the obstruction by means of enemas, and by rubbing the abdomen with castor oil, to one ounce of which, two drops of croton oil were added; friction appears to be of essential service in these cases.

The following statement has been sent to us by Mr. Row LEY, of the Borough of Soutllwark.

"The case of dry gangrene related in the 194th Number of 'I'HE Lancer, p. 224, was under my treatment in St. Saviour's Worh. house for ten weeks, and certainly there was no poultice or lotion applied.

"I consider that when the separation takes place, the discharge from the living surface will rapidly exhaust the patient; and with that idea, I ordered the dead portion to be kept dry with hair powder, and when the woman was sent to the hospital, she was not in that weak condition that you would imagine from the nature of the case."

EXPANSION SHOE $v$, FROG-PRESSURE.

\section{To the Editor of The Lavcri.}

$\mathrm{S}_{\mathrm{IR},-\Lambda \text { mong }}$ other trifing inacutracies into which Mr. Bracy Clark, - I beg pardon, the reviewer of Mr. Coleman's work, has fallen, quite unwitringly, no doubt, are the following:- He states at page 180, "Now we can assert it as a fact, that if this (the College principle of shoeing) ever was the case, it is not so now, there being no Regiment in the service that is shod upon the principles of the College, which are those of frog-pressure," \&c. And again, at page 183, " and that not one pupil of the hundreds he (Mr. Coleman) has taught, can now be found practising these doctrines, (frog-pressure,) as every Regiment in the service can bear witness."

1 have now held for thirty years, and con- 
tinue to hold, the situation of Senior Veterinary Surgeon, in the Regiment of Artillery, during the whole of which time, "the old principle of frog-pressure" has been, and continues to be at the present day, practised with results too beneficial and notorious to admit of any doubt or dispute among impartial and candid inquirers after truth ; and I may add, that I know no dragoon Veterinary Surgeon, (and I am acquainted with several,) who shoes his regiment on other principles.

It may be worth while to inform you also, " that not one pupil of the hundreds he (Mr. Coleman) has taught, can be found practising" the doctrines promulgated by your reviewer, as every private, pablic, and army forger in the kingdom, (Mr. Bracy ('lark's excepted,) can bear witress.

If you prefer fact to assersion, or truth to falsehood, you will not hesitate to give this letter a place in "THE LANCET."

I am Sir,

Your obedient Sevant, John Percival,

Senior V.S. Royal Artill.

Royal Horse Infirmary, Woolwich, May, 15.

As we are anxious that our readers should receive correct information on every subject discussed in the pages of this Journal, we have thought it a duty to insert the above letter, and shall take the liberty of offering a few comments on the matter to which it relates; and first we can assure Mr. PERcIVAL, that if his "pressure" be as inapplicable to the frog as his guess is to the name of the "reviewer" of Mr. Coleman's toadlike quarto, that we have much reason for congratulating the horses of the Artillery Corps, at Woolwich. In the notices to correspondents of our last, we took the liberty to ask Mr. Percival " how he effected frog-pressure," to which he replies in a note, " the question at issue is not how frog pressure is effected, but simply whether it is or is not practised in the Artillery and Cavalry services ;" Mr. P. adds " any day it may be convenient to you to come to Woolwich, I will demonstrate to you that such is the practice in the former; and after that I will take steps to show to what extent it prevails in the latter."

Previously to receiving this note, we re- quested a friend to visit the Artillery Corps, for the purpose of inspecting the "frog pressure" machinery, and of the results of his investigation we shall speak hereafter.

Pursuing, therefore, our first view of the subject, which actual observation has confirmed, we shall presently prove the truth of the position, " that no regiment in the British service is shod upon Mr. Coleman's principles of frog-pressure."

It is one thing to say that such principles are intended to be practised, and another to show that they are really adopted; or, to continue the quotation in our Review, where it becomes definite, which Mr. Percival prudently avoids, " these principles of frog-pressure, to be carried into real effect, would require a thin heeled shoe, as proposed by its inventor, La Fosse, who himself afterwards abandoned it, nor was it ever after resumed in France." Very well! Now if this, the Professor's thin-heeled shoe, three times as thick at the toe as at the heels, or any other direct frog-pressure agent, the patent artificial frog, the patent frog bar, or spit bar shoes, if any of these are actually worn by all the horses in the artillery corps at Woolwich, then it must be admitted as direct evidence of what we knew before, that these shoes are used, notwithstanding their manifold disadvantages; but that this is not the case is scarcely credible, after such $a$ formal declaration of principle. But Mr. Percival uses level shoes, and merely professes the doctrines of frog pressure, and is really only giving to this organ, as far as shoeing can permit, what Mr. B. Clark allows to be proper and necessary, "such a moderate share of pressure as it receives in its natural state," and by no means fulfiing these absurd opinions of the Professor, to the extent in which they are taught in his works and lectures. It is not meant to assert, that such things are never put on at Woolwich, but from our Friend's inspection we know, that by far the greater part of the Artillery Corps are shod without any devia- 
tion in principle from the common shoe. What then becomes of this boasted principle, so " notoriously beneficial?" if it is not good in general, it is good for nothing, and if Mr. Percival sometimes gently squeezes the frogs of horses committed to his care, either out of sincere kindness and compassionate sympathy for the suffering which none of his plans will prevent, or because it is his wish to please his friend and patron the professor; in either case, we can only lament that there is one veterinary surgeon so lost in this delusive folly. And, withal, Mr. Percival is so blinded by partiality as not to see, that while advocating frogpressure, he himself cannot generally practise it, and attacks our general position, " that no regiment is shod upon Mr. Coleman's principles," merely because, in compliance with this exploded nonsense, he himself occasionally uses these fanciful shoes. We apprehend that some time will elapse before this subject can be set at rest, meanwhile we assure Mr. Percival, that we have carefully investigated both the works of Mr. Coleman and of Mr. Bracy Clark, and we do not hesitate to own ourselves as the decided disciples of the doctrines of the latter gentleman, whose principles of shoeing as described in his work on the expansion shoe, we are of opinion, embrace all the philosophical principles of the art. In our next we shall revert to the subject.

\section{MEDICAL SCHOOL OF GLASGOVI.}

I REJoICE to find in two late Numbers of your extensively circulated and admirably conducted Journal, allusion made to the vacant Chair of the Theory and Practice of Medicine in this University. The interest which you take in every thing that regards the respectability, welfare, and improvement of your profession, and the manly and uncompromising spirit which you have so uniformly evinced, induce me to cherish the hope, that your exertions will be devoted on the present occasion in holding up to the profession, and public at large, the necessity and importance of appointing to a situation of such interest and responsibility, some person of acknowledged eminence, who will do credit to the rising fame and reputation of the Glasgow College. I am aware that the appointment belongs to the Crown, but in the present crisis of public affairs it is matter of doubt whether the Duke of Mon. trose, who is Chancellor of the University, and from whom all the recent appointments have emanated, will be allowed to nominate to this situation, or whether the power shall be retained by the Ministers of the Crown, and thus made subservient to their political influence. It is generally believed, however, that no person has as yet received a pro. mise of the gift, and there is therefore considerable doubt as to who is likely to prove the successful candidate. We have been told that Montrose declines, since he has ceded the situation in his Majesty's household, to ask a favour of the present Administration, but that he expects, as head of the College, that this will be given to him unsolicited, otherwise he resigns the office of Chancellor. This can be a matter, I conceive, of very little moment, so far as regards the selection of a properly qualified individual; but it will no doubt affect, very materially, the success of various candidates who hare been laying trains for years past to acquire the smile and favour of a person who, from the unexpected change in public affairs, may now be unable to yield them assistance, or favour their darling and ambitious pretensions. I must do the Duke of Montrose the credit of having generally displayed an anxiety in filling the vacant medical chairs of this college by men of distinguished eminence, and that the fame and celebrity of the University have been increased by all his recent appointments, with only one exception, which I need hardly particularise. But it has also been notorious, that politics, in which his Grace has been long a decided partisan, have been frequently made the test of a man's pretensions to professional advancement. The political faith and belief of the candidate require first to be ascertained, and if these are sound and genuine, then his professional talents become an object of secondary consideration. This is a state of matters which is highly to be deprecated; it is apt to engender in the minds of the young and am. bitious members of the profession, a sycophantic subserviency to the dispensers of the "loaves and fishes," and to kindle a sec. tarian zeal in political affairs, too powerfully calculated, I am afraid, to debase and injure, not only the individuals themselres who make it the stepping-stone to their ambition, but also to affect, in no trivial degree, the credit and character of a highly-useful and important profession. This is no climerical 